\title{
Influence of the particle size distribution of monomodal 316L powder on its flowability and processability in powder bed fusion
}

\author{
Marvin A. Spurek ${ }^{1,2}$ (D) Lukas Haferkamp ${ }^{1,2} \cdot$ Christian Weiss $^{3} \cdot$ Adriaan B. Spierings $^{1} \cdot$ Johannes H. Schleifenbaum $^{4}$. \\ Konrad Wegener ${ }^{2}$
}

Received: 23 December 2020 / Accepted: 12 November 2021 / Published online: 6 December 2021

(c) The Author(s) 2021

\begin{abstract}
Powder bed fusion (PBF) is the most commonly adopted additive manufacturing process for fabricating complex metal parts via the layer-wise melting of a powder bed using a laser beam. However, the qualification of PBF-manufactured parts remains challenging and expensive, thereby limiting the broader industrialization of the technology. Powder characteristics significantly influence part properties, and understanding the influencing factors contributes to effective quality standards for PBF. In this study, the influence of the particle size distribution (PSD) median and width on powder flowability and part properties is investigated. Seven gas-atomized SS316 powders with monomodal PSDs, a median particle size ranging from $10 \mu \mathrm{m}$ to $60 \mu \mathrm{m}$, and a distribution width of $15 \mu \mathrm{m}$ and $30 \mu \mathrm{m}$ were analyzed and subsequently processed. The PBFmanufactured parts were analyzed in terms of density and melt pool dimensions. Although powder flowability was inversely related to the median particle size, it was unrelated to the distribution width. An inverse relationship between the median particle size and the part density was observed; however, no link was found to the distribution width. Likely, the melt pool depth and width fluctuation significantly influence the part density. The melt pool depth decreases and the width fluctuation increases with an increasing median particle size.
\end{abstract}

Keywords Powder bed fusion (PBF) · Particle size distribution (PSD) - Powder flowability $\cdot 316 \mathrm{~L}$ stainless steel $\cdot$ Part density $\cdot$ Melt pool dimensions

\section{Introduction}

Additive manufacturing (AM) technologies enable the fabrication of complex or customized parts by layer-wise building the geometry of the digital design from feedstock material. Powder bed fusion (PBF) is the most widely used AM process for fabricating metal parts, and has evolved into

Marvin A. Spurek

spurek@inspire.ethz.ch

1 Inspire AG, Innovation Center for Additive Manufacturing Switzerland (icams), Fürstenlandstrasse 122, 9014 St. Gallen, Switzerland

2 Swiss Federal Institute of Technology, ETH Zurich, Institute of Machine Tools and Manufacturing (IWF), Leonhardstrasse 21, 8092 Zurich, Switzerland

3 Fraunhofer Institute for Laser Technology ILT, Steinbachstraße 15, 52074 Aachen, Germany

4 RWTH Aachen University, Chair of Digital Additive Production, Steinbachstraße 15, 52074 Aachen, Germany a sophisticated technology in various industrial fields such as aerospace, medical, defence industry, as well as tool and mould making. The PBF process is characterized by the layer-wise melting of a metal powder bed using a laser beam. Inherently, the process and the part quality are significantly influenced by the powder properties $[1,2]$. The conventional powder properties that are analyzed include the particle size distribution (PSD), particle morphology, powder flowability, and the chemical composition, as demonstrated in recent reviews on powder characterization methods for additive manufacturing [3-5].

To date, several researchers have investigated the influence of the PSD on the PBF process and the part quality. Meiners [6] determined that significantly coarse powder negatively impacts part density. Spierings et al. [1] later verified the influence of the PSD on the process window, mechanical properties, and surface roughness of parts made from 316L. The coarse powder yielded a lower part density than the fine powder. Liu et al. [7] compared part density, surface roughness, mechanical properties, and the hardness 
of parts made from two different 316L powders, and concluded that the differences they determined are triggered by the difference in PSD. Seyda [8] studied the influence of PSD on the mechanical properties and determined a correlation between the PSD of Ti-6Al-4V powder and the tensile strength of the components. Lutter-Günther et al. [9] investigated the influence of the PSD of AlSi10Mg powder on the part density and determined that the most coarse powder yields the highest density. They attribute this phenomenon to powder agglomerates formed in the fine powder and further speculate that large surface area of the fine powder facilitated an increase in humidity from the air, which might have triggered agglomeration. Balbaa et al. [10] also investigated the influence of the PSD of AlSi10Mg powder on the part density and determined that coarse powder yielded high part density. The authors discuss that the poor flowability of fine powders leads to agglomerations in the powder bed, which triggers porosity. Furthermore, they speculate that fine powder contains more oxides on the particle surfaces, which creates gas bubbles and causes porosity in the parts. Pleass and Jothi [11] characterized and processed three IN625 powders with different PSDs and determined that the fine powder was not processable owing to poor flowability. The density difference between parts made from the other two powders was negligible and the authors inferred that beyond an adequate level of flowability, density primarily depends on processing parameters. Gürtler et al. [12] investigated the influence of the PSD on the melt pool dynamics, including the resulting defects in the work piece via experiments and simulation. They processed and simulated the processing of seven bimodal AlSi10Mg powders and determined that small particles compensate defects on the powder bed better, which leads to a more stable melt pool.

Despite the existing research, recent studies $[3,13,14]$ still emphasise the need to bridge the gap between powder and part properties. In most of the related studies on the influence of the PSD on the PBF process, few commercially available PBF powders with similar PSDs were adopted. According to the studies on the influence of the PSD of $316 \mathrm{~L}$ powder on part density, a very coarse powder yields a low part density. However, the upper threshold of the particle size, beyond which the part density is negatively affected, remains unclear. It was also demonstrated that although fine powders flow worse than coarse powders, it remains open where the lower threshold of the particle size is, below which the flowability is insufficient to create adequate layers that negatively affects the part density. These missing knowledge is also reflected in the lack of broadly accepted powder requirements and quantified standards for powder qualification. There is an absence quantitative studies beyond the coarse and fine terms on the influence of PSD on the PBF process and part quality over the conventionally used PSD range, which, according to Debroy et al. [15], is approximately 10-60 $\mu \mathrm{m}$. Furthermore, none of these studies separate the influence of median particle size and PSD width on the process. Both factors need to be investigated to understand and quantify the influence of the PSD on the PBF process and to subsequently determine PSD requirements, which support the definition of standard procedures for the qualification of PBF powders.

This study focuses on understanding and quantifying the influence of the PSD on the PBF process. In contrast to most of the available studies, SS316L PBF powders are separated into powder fractions with tailored PSDs covering a wide range of particle sizes. Prior to the manufacturing of parts, the powders are characterized in terms of their PSD, particle morphology, and flowability. The particle morphology is analyzed to exclude a side influence by an unintended variation of particle morphology among the powders. The powder flowability is measured, as it is often considered to be an important property that ensures the processability of a powder. The influence of PSD on the PBF process is assessed by measuring the effect of the median particle size and PSD width on the density and melt pool dimensions of the fabricated parts, respectively. Part density serves as an indicator for the mechanical properties, which has been demonstrated in several studies $[16,17]$.

\section{Materials and methods}

\subsection{Sample preparation}

Commercially available gas-atomized SS316L PBF powders (Carpenter Technology Corporation and TLS Technik $\mathrm{GmbH} \& \mathrm{Co}$. Spezialpulver KG) were modified using ultrasonic sieves (Telsonic AG, Switzerland) and an air classifier (Hosokawa Alpine AG, Germany) to create six PSDs with a constant width $D_{90 \mathrm{~V}}-D_{10 \mathrm{~V}}$ of approximately $15 \mu \mathrm{m}$ and a median particle size between $\mathrm{D}_{50 \mathrm{~V}}=10 \mu \mathrm{m}$ and $\mathrm{D}_{50 \mathrm{~V}}=$ $60 \mu \mathrm{m}$, which varied in steps of $10 \mu \mathrm{m}$. An additional powder sample of an as-bought PBF powder was selected, and it has a median particle size $\mathrm{D}_{50 \mathrm{~V}}=30 \mu \mathrm{m}$ and a relatively larger PSD width of approximately $\mathrm{D}_{90 \mathrm{v}}-\mathrm{D}_{10 \mathrm{~V}}=30 \mu \mathrm{m}$. Before processing, all powders were characterized using different methodologies.

\subsection{Powder characterization}

\subsubsection{Particle size distribution}

The PSD was determined using an LS230 laser diffraction device (Beckman Coulter Inc., USA). Therefore, the powder samples were dispersed in ethanol and three measurements were obtained at a pump speed of 90 RPM. Images of powder particles were taken using an FEI Quanta 200F scanning 
electron microscope (SEM) (Thermo Fisher Scientific Inc., USA) at an accelerating voltage of $20 \mathrm{kV}$.

\subsubsection{Particle morphology}

A powder sample of each powder was dispersed on a petri dish and pictures were taken using a DM6 optical microscope (Leica Microsystems GmbH, Germany) under reflected light in the bright field mode. Pictures showing agglomerates were manually removed. The remaining minimum 3000 particles per sample were analyzed with an inhouse written algorithm, and the shape factors were calculated according to Equations (1) and (2). Subsequently, means and standard deviations of the respective shape factors were calculated.

The circularity $f_{\text {circ }}$ is calculated according to the formula adopted by Bouwman [18] as:

$f_{\text {circ }}=\frac{4 \pi A}{P^{2}}$

with $A$ being the area and $P$ being the perimeter of the projected particle.

The aspect ratio $A_{R}$ is calculated according to the equation adopted by Merkus [19] as:

$A_{R}=\frac{\mathrm{D}_{\text {Fmin }}}{\mathrm{D}_{\text {Fmax }}}$

where $\mathrm{D}_{F \min }$ and $\mathrm{D}_{F \max }$ represent the minimum and maximum Feret diameters of the projected particle, respectively.

The circularity determines the roundness of the particle while the aspect ratio describes the elongation of the particle. An ideal spherical particle has a circularity and aspect ratio of 1 .

\subsubsection{Flowability}

A revolution powder analyzer (RPA) (Mercury Scientific Inc., USA) was adopted to assess the powders' flowability. A tapped powder sample with a volume of $100 \mathrm{~cm}^{3}$ was fed into the drum $\left(\mathrm{d}_{\mathrm{drum}}=100 \mathrm{~mm}\right)$ and rotated at a given speed $(36 R P M)$. The measurement principle is depicted in Fig. 1 .

Three measurements per sample were performed with 128 avalanches detected in each measurement, and the mean and standard deviation of the avalanche angle and surface fractal were calculated. The avalanche angle $\alpha_{A}$ is defined as the angle between the powder surface line and the horizontal, and is detected by a camera at the time an avalanche occurs. The surface fractal $f_{S}$ measures the smoothness of the powder surface after an avalanche has occurred and is an indicator of the tendency of a powder to form agglomerates. In general, a small avalanche angle and surface fractal indicate good flowabiliy [21].

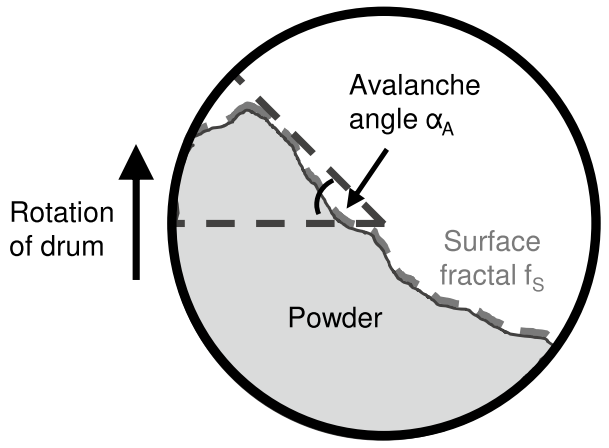

Fig. 1 Determination of the avalanche angle and surface fractal in an RPA [20]

Table 1 Description of powder flow behavior in terms of Hausner ratio [22]

\begin{tabular}{ll}
\hline Hausner ratio $\mathrm{H}[-]$ & Flow description \\
\hline $1.00-1.11$ & Excellent \\
$1.12-1.18$ & Good \\
$1.19-1.25$ & Fair \\
$1.26-1.34$ & Passable \\
$1.35-1.45$ & Poor \\
$1.46-1.59$ & Very poor \\
$>1.60$ & Non-flowable \\
\hline
\end{tabular}

The Hausner ratio $(\mathrm{H})$ [22] is another widely used number in evaluating the flowability of a powder by utilizing the classification presented in Table 1 [5]. The Hausner ratio is defined as the ratio of the tap density and apparent density of a powder, which were measured three times according to ASTM B417-18 [23] and ASTM B527-15 [24], respecively. Subsequently, means and standard deviations of the apparent density, tap density and the Hausner ratio were calculated.

\subsection{Part production}

Cubic test geometries with dimensions $10 \times 10 \times 10 \mathrm{~mm}$ were manufactured using a Concept Laser M2 PBF machine (Concept Laser GmbH, Germany), which is equipped with a Nd-YAG fiber laser with a maximum continuous laser power and wavelength of $400 \mathrm{~W}$ and $1064 \mathrm{~nm}$, respectively. Five parts per scan speed were fabricated onto stainless steel substrate plates with every powder adopting the process parameters presented in Table 2. Prior to the fabrication of test geometries, the laser beam diameter at the working plane was measured to be $105 \mu \mathrm{m}$ using a beam profiler camera SP928 (Ophir Spiricon Europe GmbH, Germany). The reported laser powers are output laser powers, which were measured with a laser power sensor FL-1100A-BB-65 (Ophir Spiricon Europe GmbH, Germany). 
Table 2 PBF process parameters

\begin{tabular}{lll}
\hline Parameter & \multicolumn{2}{c}{ Value } \\
\hline Laser power $P_{L}$ & {$[\mathrm{~W}]$} & 180 \\
Scan speed $v_{s}$ & {$[\mathrm{~mm} / \mathrm{s}]$} & $1000,1250,1500,1750,2000$ \\
Hatch spacing $h_{s}$ & {$[\mu \mathrm{m}]$} & 75 \\
Layer thickness $t_{l}$ & {$[\mu \mathrm{m}]$} & 30 \\
Beam diameter $d_{\text {spot }}\left(1 / e^{2}\right)$ & {$[\mu \mathrm{m}]$} & 105 \\
Recoater velocity & {$[\mathrm{mm} / \mathrm{s}]$} & 100 \\
Recoater type & - & Silicon-reinforced brush \\
Scan pattern & - & $90^{\circ}$ alternating \\
Shielding gas & - & Nitrogen \\
\hline
\end{tabular}

\subsection{Part characterization}

The parts were cut off the substrate plate, and the density and melt pool dimensions were evaluated.

\subsubsection{Density measurement}

The part densities $\rho_{r}$ of five parts per scan speed were measured via the Archimedes method [25] utilizing an AE200 balance with the measuring unit AB33360 (Mettler Toledo Inc., USA) and calculated according to:

$\rho_{r}=\frac{\frac{m_{a}}{m_{a}-m_{a c}}\left(\rho_{a c}-\rho_{a}\right)+\rho_{a}}{\rho}$

where $m_{a}, m_{a c}, \rho_{a c}, \rho_{a}$, and $\rho$ represent the mass measured in ambient air, mass measured in aceton, density of aceton (temperature corrected), density of ambient air (temperature corrected), and density of SS316L, respectively. Subsequently, the mean and standard deviation of $\rho_{r}$ per powder and scan speed were calculated.

\subsubsection{Determination of melt pool dimensions}

To determine the melt pool dimensions, one part per powder fabricated with a scan speed of $\mathrm{v}_{\mathrm{s}}=1000 \mathrm{~mm} / \mathrm{s}$ was cut perpendicular to the scan direction of the top layer as illustrated in Fig. 2a, embedded in epoxy resin, ground using $\mathrm{SiC}$ grinding paper (320, 600 and 1200 grit sizes), polished with diamond suspension up to $0.5 \mu \mathrm{m}$, and etched in $\mathrm{V} 2 \mathrm{~A}$ etchant at $60^{\circ} \mathrm{C}$ for $30 \mathrm{~s}$. Images of the melt pool cross sections of the top layer were taken at 200× magnification using a DM6 optical microscope (Leica Microsystems GmbH, Germany). The melt pool depth, cross-sectional area, and scan track width (Fig. 2b) of $n=105$ melt pools per part were measured using a semi-automatic Matlab (The MathWorks Inc., USA) script based on the image segmentation toolbox. Subsequently, means and standard deviations of the respective melt pool dimensions were calculated. To determine statistically significant differences between group means, Welch's analysis of variance and the Games-Howell post hoc test were applied. Statistically significant differences between group variances were determined using Levene's test.

\section{Results and discussion}

\subsection{Particle size distribution}

The volume-weighted particle size distributions of the seven powders measured by laser diffraction are illustrated in Fig. 3 and the $D_{10 V}, D_{50 V}, D_{90 \mathrm{~V}}$ and PSD width defined by $D_{90 V}-D_{10 V}$ are presented in Table 3 . The designation of each powder was chosen according to its $D_{50 \mathrm{~V}}$. The results show the variation of the median particle size $D_{50 \mathrm{~V}}$ in steps of approximately $10 \mu \mathrm{m}$ between $10 \mu \mathrm{m}$ and $60 \mu \mathrm{m}$, as well as narrow PSD widths $D_{90 \mathrm{~V}}-D_{10 \mathrm{~V}}$ between $13.8 \mu \mathrm{m}$ and $21.4 \mu \mathrm{m}$. The as-bought PBF powder P29w has a similar $D_{50 \mathrm{~V}}$, but a twice as large PSD width compared to the $\mathrm{P} 28$ powder. These two powders are used to study the influence of the PSD width on the process, whereas the six powders except P29w are utilized to study the influence of the median particle size on the process. The PSD differences among the powders are visualized by the SEM images depicted in Fig. 4.
Fig. 2 Analyzed cross sections of parts (a) and measured melt pool dimensions (b) (a)

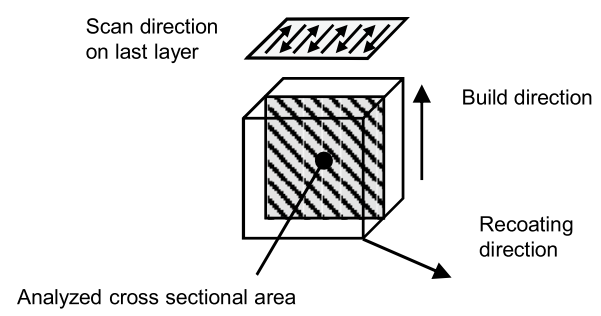

(b)

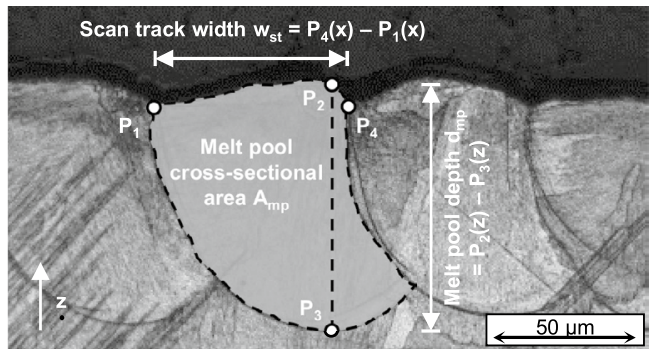




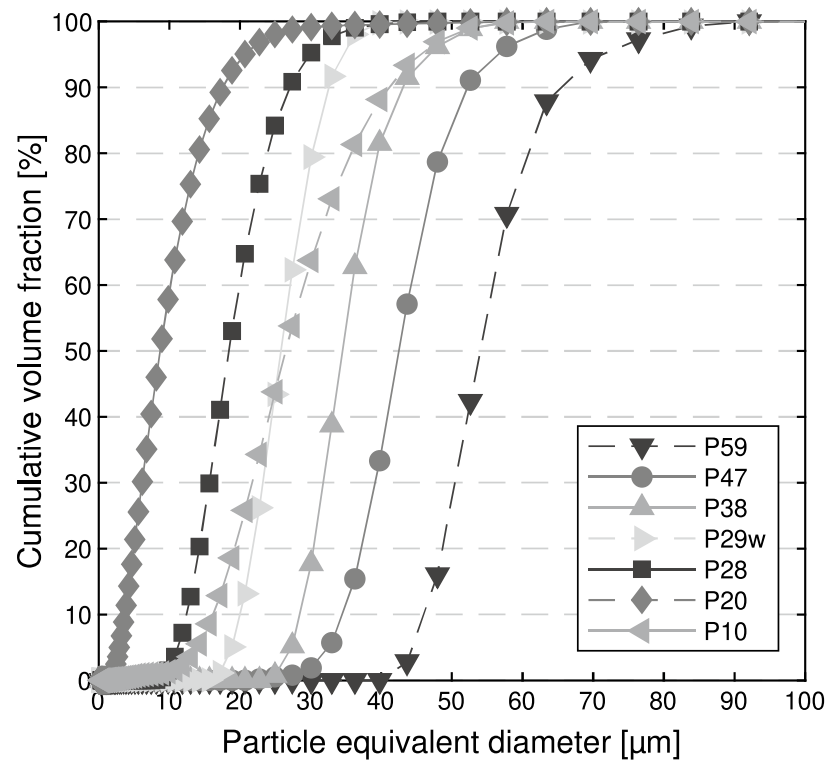

Fig. 3 Cumulative particle size distributions of the seven SS316L powders

\subsection{Particle morphology}

The results of the particle morphology analysis are summarized in Table 4 . The fine powders exhibit a higher circularity and aspect ratio than the coarse powders.

The differences are also significant when comparing the SEM images presented in Fig. 4. The seven powders consist of almost spherical $\left(f_{\text {circ }} \geq 0.84\right)$, slightly elongated $\left(A_{R} \geq 0.81\right)$ particles. Haferkamp et al. [26] demonstrated that the particle shape does influence flowability and part density; however, this assertion only holds, up to a particle circularity of approximately 0.8 . Riener et al. [16] demonstrated that plasma-atomized AlSi10Mg powder with an aspect ratio of approximately 0.95 yields higher part densities compared to gas-atomized powders with aspect ratios between approximately 0.84 and 0.89 . Because the mean circularity and aspect ratio of the powders used in this work is $f_{\text {circ }} \geq 0.84$ and $0.81 \geq A_{R} \geq 0.84$, respectively, it is inferred that the particle shape differences among the powders does not affect the powder flowability or part density.

Table 3 Laser diffraction PSD

\begin{tabular}{|c|c|c|c|c|c|c|c|c|}
\hline & & P10 & P20 & P28 & P29w & P38 & P47 & P59 \\
\hline$D_{10 \mathrm{~V}}$ & {$[\mu m]$} & 4.0 & 13.6 & 21.9 & 17.7 & 31.2 & 37.8 & 50.5 \\
\hline$D_{50 \mathrm{~V}}$ & {$[\mu m]$} & 9.5 & 20.2 & 28.3 & 29.1 & 37.9 & 46.7 & 59.3 \\
\hline$D_{90 \mathrm{~V}}$ & {$[\mu m]$} & 19.3 & 29.7 & 35.8 & 45.1 & 47.3 & 57.3 & 71.9 \\
\hline$D_{90 \mathrm{~V}}-D_{10 \mathrm{~V}}$ & {$[\mu m]$} & 15.2 & 16.1 & 13.8 & 27.4 & 16.1 & 19.5 & 21.4 \\
\hline
\end{tabular}

(a)

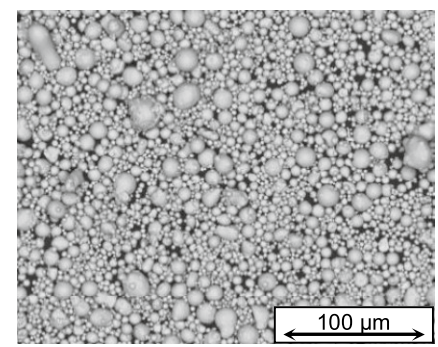

(e)

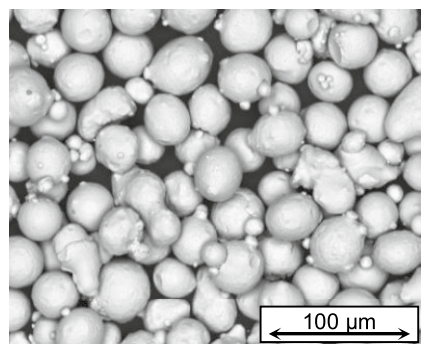

(b)

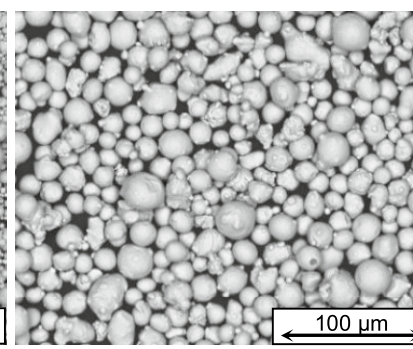

(f)

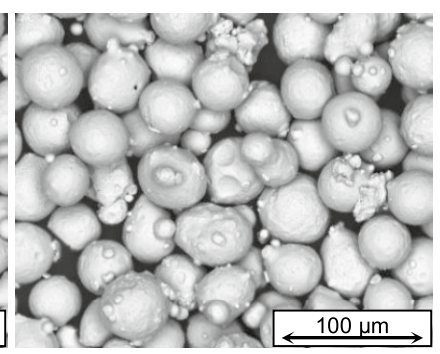

(c)

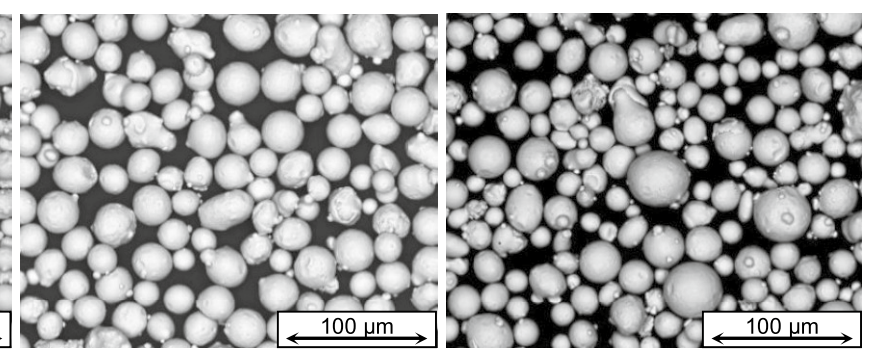

(g)

Fig. 4 SEM images of powder particles. P10 (a), P20 (b), P28 (c), P29w (d), P38 (e), P47 (f), P59 (g) 
Table 4 Particle morphology (mean $\pm S D$ ) obtained from optical microscopy

\begin{tabular}{|c|c|c|c|c|c|c|c|c|}
\hline & & P10 & $\mathrm{P} 20$ & P28 & $\mathrm{P} 29 \mathrm{w}$ & P38 & P47 & P59 \\
\hline & & $0.95 \pm 0.07$ & $0.90 \pm 0.09$ & $0.90 \pm 0.10$ & $0.92 \pm 0.09$ & $0.89 \pm 0.11$ & $0.84 \pm 0.14$ & $0.88 \pm 0.11$ \\
\hline & {$[-]$} & $0.85 \pm 0.10$ & $0.81 \pm 0.12$ & $0.82 \pm 0.12$ & $0.83 \pm 0.12$ & $0.82 \pm 0.11$ & $0.81 \pm 0.12$ & $0.82 \pm 0.12$ \\
\hline
\end{tabular}

(a)

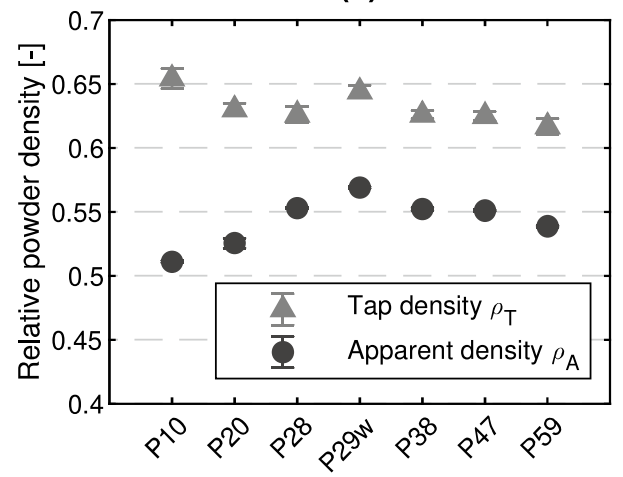

(b) ties (a) Hausner ratio (b) and avalanche angle, as well as surface fractal (c) of the SS316L powders $($ mean $\pm S D)$

\subsection{Flowability}

The results of the powder density and powder flowability analyses are visualized in Fig. 5. Regarding the Hausner ratio (Fig. 5b) and Table 1), the powders with $D_{50 \mathrm{~V}}$ $=28 \mu \mathrm{m}$ exhibit a good flowing behavior, whereas the finer ones exhibit a fair (P20) or passable (P10) flowing behavior. The results obtained with the RPA lead to the same conclusion (Fig. 5c). The larger means and standard deviations of both the avalanche angle and surface fractal of the two finest powders indicate the formation of agglomerates. This can be explained by the ratio of interparticle forces, mostly van der Waals forces, to gravitational forces, which increases with the amount of fine particles in a powder [27]. A larger PSD width appears to increase both the apparent and tap densities comparing P28 and P29w (Fig. 5a) as expected, based on theoretical considerations regarding packing density [6]; however, it does not significantly influence flowability (Fig. 5b, c).

\subsection{Density}

The density of a PBF-manufactured part is a major indicator of its mechanical strength [8]. Fig. 6 presents the relative density per scan speed and powder. At the lowest scan speed adopted, all powders provide parts with a density larger than $99.4 \%$. According to the widely used definition of the volumetric energy density by Stoffregen et al. [28], the energy input into the melt pool is inversely related to the scan speed. Therefore, increasing the scan speed decreases the part density in the conduction mode region of the process window [28]. In this region, the reduction of the part density is due to lack of fusion porosity, as determined in different studies [29, 30]. This effect can be observed by comparing the obtained densities at varied scan speeds for all powders used. However, for parts made from the coarse powders, this effect is significantly increased in the following regions: P38: $\mathrm{v}_{\mathrm{s}}=2000 \mathrm{~mm} / \mathrm{s}, \mathrm{P} 47: \mathrm{v}_{\mathrm{s}}=1500 \mathrm{~mm} / \mathrm{s}$, P59: $\mathrm{v}_{\mathrm{s}}=1250 \mathrm{~mm} / \mathrm{s}$. For example, at $\mathrm{v}_{\mathrm{s}}=2000 \mathrm{~mm} / \mathrm{s}, \mathrm{P} 38$ exhibits a drop in mean density of $2 \%$, whereas the same decrease in mean density occurs at $4 \%$ and $5 \%$ for P47 and 


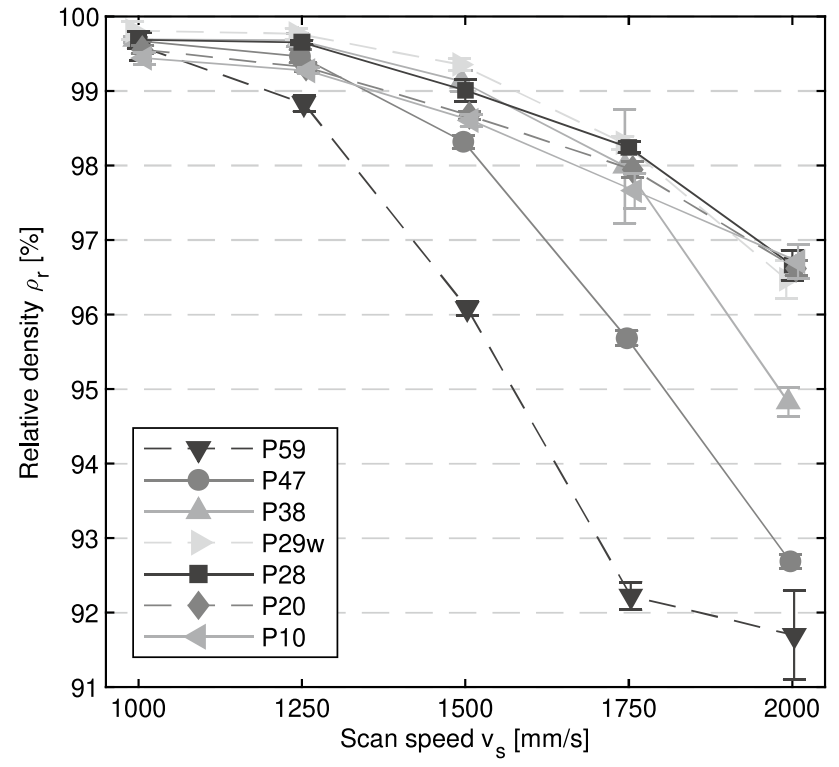

Fig. 6 Relative part density (mean $\pm S D$ ) of parts manufactured at $P_{L}=180 \mathrm{~W}$ and varied scan speeds (other process parameters fixed, see Table 2)

P59, respectively. Comparing the density curves for P28 and P29w suggests the PSD width does not influence density. When increasing the scan speed, porosity is mostly triggered by lack of fusion defects, which is attributed to insufficient bonding of the scan tracks and layers [15]. Because for fixed process parameters outside the optimum using powders with a varied median particle size leads to a different amount of lack of fusion defects, the melt pool dimensions appear to be influenced by the median particle size. The threshold beyond which the part density is negatively affected is in the range of $28 \mu \mathrm{m}<\mathrm{D}_{50 \mathrm{~V}}<38 \mu \mathrm{m}$, because $\mathrm{P} 38$ is the finest powder that exhibits a significant decrease in density within the range of investigated scan speeds.

\subsection{Melt pool dimensions}

Images of the part top surface depicting the scan tracks of the last layer are presented in Fig. 7. The overall layer surface appears more regular for fine powders and deteriorates in the direction of increasing median particle size. Independent of the powder used, there are particles that are partially fused to the layer surface. However, using more coarse powder leads to larger particles being partially fused to the layer surface. The most coarse two powders (Fig. 7f, g) also exhibit unfavorable regions of material accumulation. Comparing Fig. 7a, d, g reveals differences in the fluctuation of the scan track width among the powders. Fine powders lead to more regular scan tracks compared to coarse powders, where the scan track edges are corrugated.

To assess the influence of the median particle size on the melt pool, which triggers the differences in the scan track geometry between the powders, the melt pool dimensions were measured, and the obtained results are summarized in Fig. 8. For a given material and machine configuration, the energy input into the melt pool, which is reflected by the volumetric energy density, is the most important influencing factor for the melt pool size, as demonstrated by Dilip et al. (a)

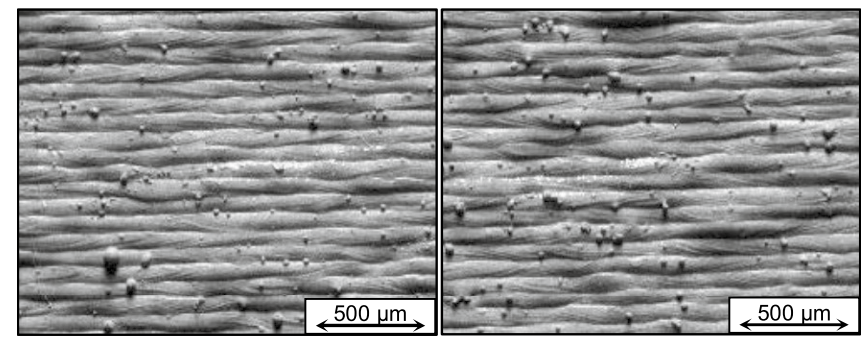

(c)

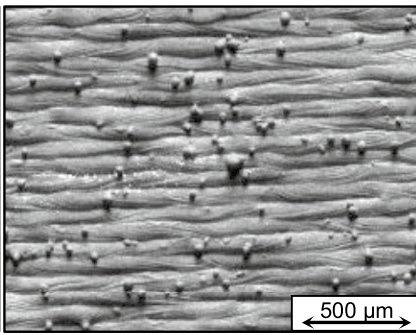

(d)

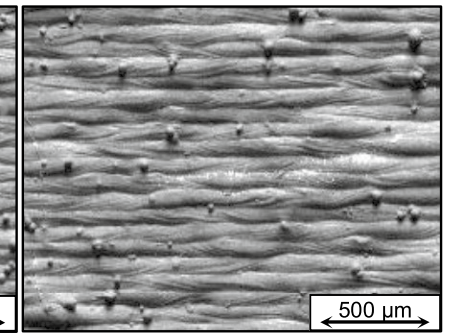

(e)

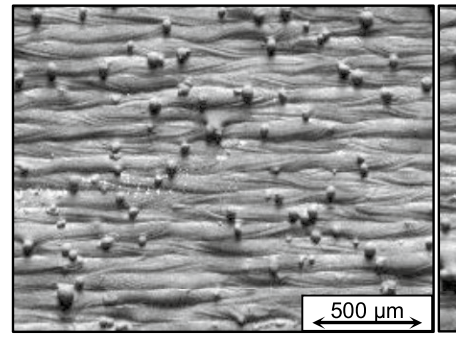

(f)

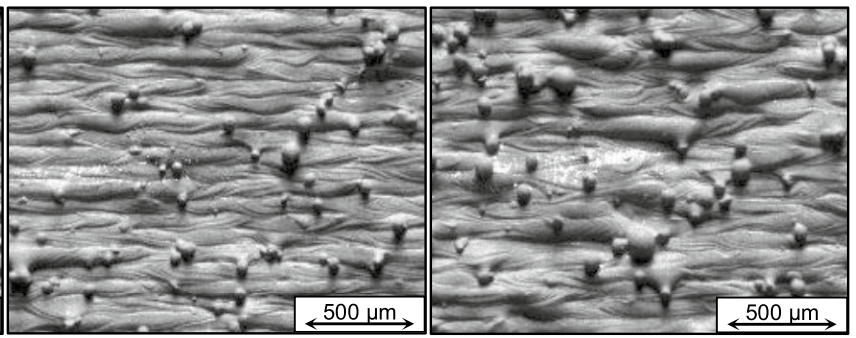

Fig. 7 Top surface images depicting the scan tracks of the last layer of the dense parts $\left(\rho_{r}>99.4 \%\right)$ manufactured at $\mathrm{v}_{\mathrm{S}}=1000 \mathrm{~mm} / \mathrm{s}$ using the seven SS316L powders specified in Table 3. P10 (a), P20 (b), P28 (c), P29w (d), P38 (e), P47 (f), P59 (g) 
Fig. 8 Melt pool dimensions $($ mean $\pm S D)$ of dense parts $\left(\rho_{r}>99.4 \%\right)$ manufactured at $\mathrm{v}_{\mathrm{s}}=1000 \mathrm{~mm} / \mathrm{s}$. Melt pool cross-sectional area (a), melt pool depth (b), scan track width (c), and standard deviation of the scan track width (d) fitted with a first order exponential function (a)

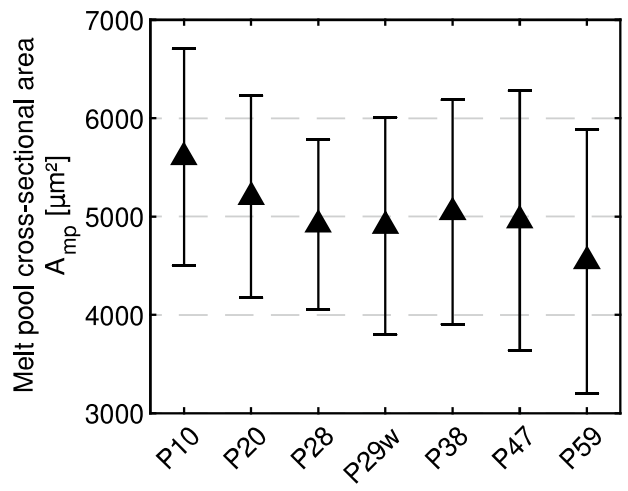

(c)

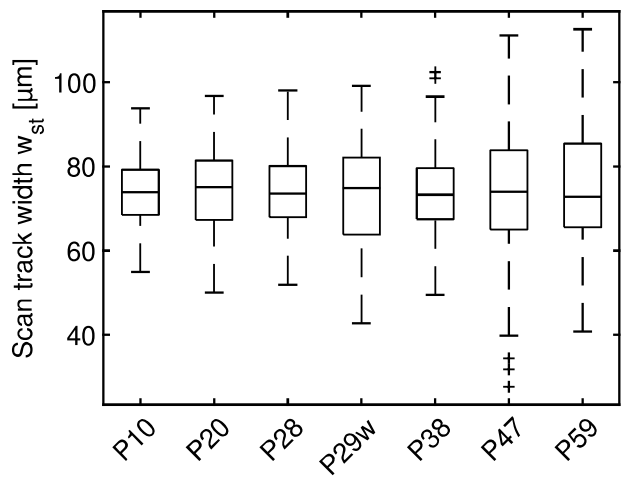

(b)

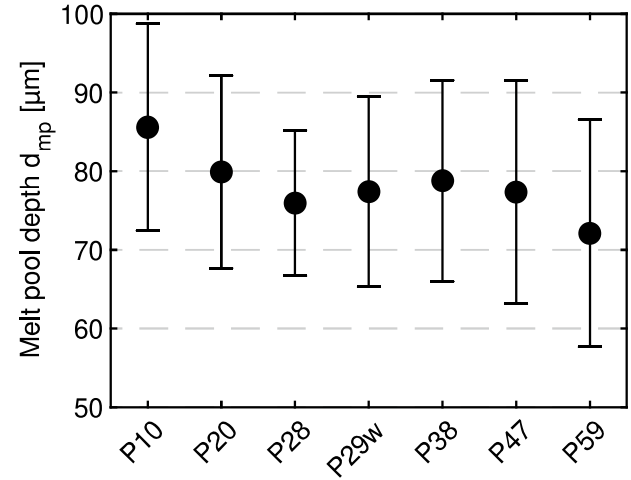

(d)

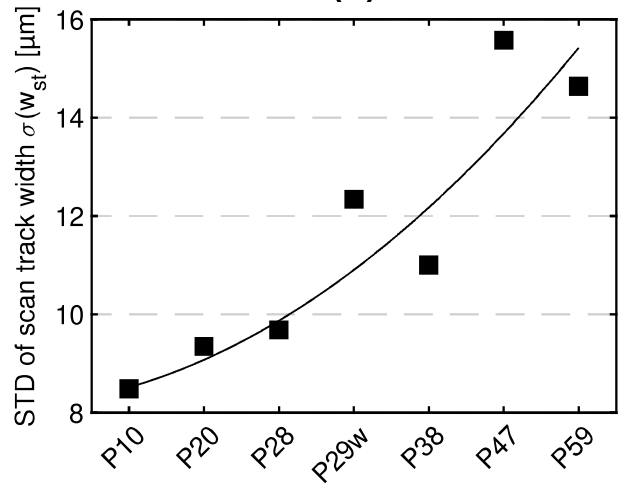

[30] and Guo et al. [31]. However, comparing the melt pool cross-sectional areas of the different powders depicted in Fig. 8a indicates a significant influence of the median particle size on the melt pool size $(p<0.001)$. Fine powders lead to a larger mean melt pool cross-sectional area than that of coarse powders, which is mainly due to a larger mean melt pool depth (Fig. 8b). In particular, the mean melt pool depth of the most coarse powder (P59) is significantly smaller than that of all the other powders $(p \leq 0.014)$. Mukherjee et al. [32] identified an insufficient penetration of the melt pool into the previous layer as one of the major reasons for lack of fusion porosity. Regarding the melt pool depth depicted in Fig. 8b, all powders exhibit dense samples $\left(\rho_{r}>99.4 \%\right)$. However, increasing the scan speed decreases the melt pool depth in PBF, as demonstrated by Dilip et al. [30] and Guo et al. [31]. Therefore, the minimal required melt pool depth, which ensures sufficient bonding with the underlying layer, as explained by Mukherjee et al. [32], is expected to be reached with coarse powders already at lower scan speeds compared to fine powders. Hence, the effect of the median particle size on the melt pool depth is suggested to be a reason for different part densities at high scan speeds presented in Fig. 6.
In addition to the effect of the median particle size on the melt pool cross-sectional area and melt pool depth, the median particle size influences the melt pool width quantified by the scan track width in Fig. 8c, d. Although the mean scan track width is unaffected by the median particle size $(p=0.998)$, the standard deviation of the scan track width, which was qualitatively analyzed in Fig. 7, significantly increases with an increasing median particle size $(p<0.001)$ and PSD width $(p=0.004)$, as illustrated in Fig. 8d. Similar results, which indicate an increased fluctuation of the scan track width leading to higher corrugation of the scan track edge for a coarse powder compared to a fine powder, were obtained by Lee et al. [33] via simulation. Large fluctuations of the melt pool width can be an indicator of capillary instability, as discussed by Gusarov et al. [34]. Although the presence of capillary instability adopting the coarse powders (P47 and P59) is possible, owing to the significantly higher standard deviation of the scan track width, it cannot be confirmed with certainty based on these data. However, it is assumed that the growing melt pool fluctuation for an increasing median particle size decreases the robustness of the PBF process and at least partially accounts for the density difference observed between the powders presented in Fig. 6. 


\section{Conclusion}

This study investigates the influence of the median particle size and PSD width of monomodal SS316L powders on the density and melt pool dimensions of PBF-manufactured parts. Accordingly, six gas-atomized monomodal 316L powders with constant PSD widths and median particle sizes from $10 \mu \mathrm{m}$ to $59 \mu \mathrm{m}$ were created. In addition, their properties and process performance were compared against each other and against an as-bought PBF powder with a twice as large PSD width.

The initially conducted powder analysis indicated a slightly lower particle sphericity for coarse powders than for fine powders based on circularity and aspect ratio. The flowability of a powder was significantly linked to the particle size with a worsened flowability for a median particle size of $20 \mu \mathrm{m}$ and below. This is owing to a larger ratio of interparticle to gravitational forces for fine particles, which leads to the formation of agglomerates and impedes the free-flowing behavior. No significant influence of the PSD width was determined on the flowability. In general, there was no relationship between flowability and part density determined in this study. The powder packing behavior is influenced by both median particle size and PSD width. The tap density is inversely related to the median particle size and positively related to the PSD width, leading to the highest tap density for the finest powder and second highest for the powder with the twice as large PSD width. The apparent density is also highest for the powder with the largest PSD width, but decreases in the direction of lower and higher median particle sizes owing to the formation of agglomerates and large voids between particles, respectively.

At the same process conditions, the part density is negatively affected by an increasing median particle size, thereby leading to lower part densities for coarse powders above a threshold for the median particle size found in the region $28 \mu \mathrm{m}<\mathrm{D}_{50 \mathrm{~V}}<38 \mu \mathrm{m}$. The reason for this is probably the influence of the median particle size on the melt pool size. Specifically, the melt pool depth is inversely related to the median particle size, which probably triggers more lack of fusion defects owing to insufficient bonding with the underlying layer when using coarse powders. Furthermore, the fluctuation of the melt pool width is positively related to the median particle size, leading to corrugated scan track edges when using coarse powder. The combination of reduced melt pool depth and increased fluctuation of the melt pool width indicates a reduced robustness of the PBF process, which is suggested to account for the measured density differences among the powders with varied median particle sizes.

This study verifies that the median particle size above a threshold found in the region $28 \mu \mathrm{m}<\mathrm{D}_{50 \mathrm{~V}}<38 \mu \mathrm{m}$ negatively influences the PBF process, which leads to a lower part density at the same process conditions owing to a smaller and less stable melt pool. In future work, the layer thickness and laser power should be increased to determine this threshold for high productivity parameters, which are steadily becoming more important in industrial applications. Further research utilizing pyrometry or highspeed camera imaging to measure the melt pool dimensions in situ and to observe the particle melt pool interaction during the PBF process would contribute to elucidating the effects that could not be fully unveiled in this study. Although there was no influence of the PSD width on the density identified in this study, this result is only based on data obtained from two powders with varied PSD widths. Therefore, further research with a variation of the PSD width on more levels is required to validate this finding.

Funding Open access funding provided by Swiss Federal Institute of Technology Zurich.

Data availability All data is available.

Code availability Not applicable.

\section{Declarations}

Conflict of interest The authors declare that there is no conflict of interest regarding the publication of this article.

Open Access This article is licensed under a Creative Commons Attribution 4.0 International License, which permits use, sharing, adaptation, distribution and reproduction in any medium or format, as long as you give appropriate credit to the original author(s) and the source, provide a link to the Creative Commons licence, and indicate if changes were made. The images or other third party material in this article are included in the article's Creative Commons licence, unless indicated otherwise in a credit line to the material. If material is not included in the article's Creative Commons licence and your intended use is not permitted by statutory regulation or exceeds the permitted use, you will need to obtain permission directly from the copyright holder. To view a copy of this licence, visit http://creativecommons.org/licenses/by/4.0/.

\section{References}

1. Adriaan BS, Levy G (2009) Comparison of density of stainless steel $316 \mathrm{~L}$ parts produced with selective laser melting using different powder grades. In Solid Free. Fabr. Proc., University of Texas at Austin. p 342-353. URL https://www.research-colle ction.ethz.ch:443/handle/20.500.11850/22167

2. Vanessa S, Dirk H, Claus E (2017) Relationship between powder characteristics and part properties in laser beam melting of Ti-6Al-4V, and implications on quality. J. Laser Appl., 29(2):022311. ISSN 1042-346X. 10.2351/1.4983240

3. Jun HT, Wai LEW, Kenneth WD (2017) An overview of powder granulometry on feedstock and part performance in the selective laser melting process. Addit Manuf 18:228-255. ISSN 22148604. 10.1016/j.addma.2017.10.011 
4. Slotwinski JA, Stutzman PE, Ferraris CF, Watson SS, Peltz MA, Garboczi EJ (2014) Physical and chemical characterization techniques for metallic powders. AIP Conf Proc 1581(33):1178-1183. ISSN 15517616. 10.1063/1.4864954

5. Austin TS, Caitlin SK, Ming CL, Joseph WN (2017) Powder characterisation techniques and effects of powder characteristics on part properties in powder-bed fusion processes. Virtual Phys Prototyp 12(1):3-29. ISSN 17452767. 10.1080/17452759.2016.1250605

6. Wilhelm M (1999) Direktes Selektives Laser Sintern Einkomponentiger Metallischer Werkstoffe. PhD thesis, RWTH Aachen University

7. Bochuan L, Ricky W, Christopher T, Ian A, Richard H (2011) Investigaztion the effect of particle size distribution on processing parameters optimisation in selective laser melting process. 22nd Annu Int Solid Free. Fabr. Symp. - An Addit. Manuf. Conf. SFF 2011, p 227-238,

8. Vanessa S (2018) Werkstoff- und Prozessverhalten von Metallpulvern in der laseradditiven Fertigung. PhD thesis, Hamburg University of Technology. URL http://link.springer.com/10.1007/ 978-3-662-58233-6

9. Lutter-Günther M, Horn M, Seidel C, Reinhart G (2017) Influence of particle size distribution on powder flowability and part properties in laser beam melting: Einfluss der Korngrößenverteilung auf Fließfähigkeit und Bauteilqualität beim Laserstrahlschmelzen. Rapid. Tech-International Trade Show Conf. Addit. Manuf. Proc. 14th Rapid. Tech Conf. Erfurt, Ger., p 20-22

10. Balbaa MA, Ghasemi A, Fereiduni E, Elbestawi MA, Jadhav SD, Kruth JP (2021) Role of powder particle size on laser powder bed fusion processability of AlSi10mg alloy. Addit Manuf, 37:101630. ISSN 22148604. 10.1016/j.addma.2020.101630

11. Christopher P, Sathiskumar J (2018) Influence of powder characteristics and additive manufacturing process parameters on the microstructure and mechanical behaviour of Inconel 625 fabricated by selective laser melting. Addit Manuf, 24:419-431. ISSN 22148604. 10.1016/j.addma.2018.09.023

12. Gürtler FJ, Karg M, Dobler M, Kohl S, Tzivilsky I, Schmidt M (2014) Influence of powder distribution on process stability in laser beam melting: Analysis of melt pool dynamics by numerical simulations. 25th Annu. Int. Solid Free. Fabr. Symp. An Addit. Manuf. Conf. SFF 2014, 1099-1117

13. Michael JH, Lisa AD, Jeff MR, Josh RK, Dan JT, David JS, Bradley HJ (2019) Evolution of 316L stainless steel feedstock due to laser powder bed fusion process. Addit Manuf, 25:84-103. ISSN 22148604. 10.1016/j.addma.2018.10.019

14. Silvia V, Burghardt K, Alexander K, Thomas W, Bernd K (2019) Powders for powder bed fusion: a review. Prog Addit Manuf, 4(4):383-397. ISSN 2363-9512. 10.1007/s40964-019-00078-6

15. DebRoy T, Wei HT, Zuback JS, Mukherjee T, Elmer JW, Milewski JO, Beese AM, Wilson-Heid A, Zhang W (2018) Additive manufacturing of metallic components - Process, structure and properties. Prog Mater Sci, 92:112-224. ISSN 00796425. 10.1016/j. pmatsci.2017.10.001

16. Kirstin R, Nikolaj A, Stefan Z, Robert R, Lukas H, Adriaan BS, Gerhard JL (2020) Influence of particle size distribution and morphology on the properties of the powder feedstock as well as of AlSi10Mg parts produced by laser powder bed fusion (LPBF). Addit Manuf 34:101286. ISSN 22148604. 10.1016/j. addma.2020.101286

17. Gustavo WM, Daniel OT, Julio CC, Aulio CG (2004) Effect of porosity on the tensile properties of low ductility aluminum alloys. Mater Res 7(2):221-229. ISSN 1516-1439. 10.1590/ S1516-14392004000200002

18. Anneke MB, Jaap CB, Pieter V, Wesselingh JA, Henderik WF (2004) Which shape factor(s) best describe granules? Powder Technol 146(1-2):66-72 . ISSN 00325910. 10.1016/j. powtec.2004.04.044
19. Henk GM (2009) Particle size measurements fundamentals, practice, quality. Springer, London. ISBN 9781402090158 1402090153

20. Antonio FAB (2016) Characterization and prediction of SLS processability of polymer powders with respect to powder flow and part warpage. $\mathrm{PhD}$ thesis, ETH Zurich. http://hdl.handle.net/20. 500.11850/116949

21. Spierings AB, Voegtlin M, Bauer T, Wegener K (2016) Powder flowability characterisation methodology for powder-bed-based metal additive manufacturing. Prog Addit Manuf, 1(1-2):9-20. ISSN 2363-9512. 10.1007/s40964-015-0001-4

22. Henry HH (1981) Powder characteristics and their effect on powder processing. Powder Technol 30(1):3-8. ISSN 0032-5910. https://doi.org/10.1016/0032-5910(81)85021-8. http://www.scien cedirect.com/science/article/pii/0032591081850218

23. American Society for Testing and Materials (ASTM) (2018) ASTM B417 - standard test method for apparent density of nonFree-flowing metal powders using the Carney Funnel. ASTM B. Stand., p 7-9. 10.1520/B0417-18.2

24. American Society for Testing and Materials (ASTM) (2015) ASTM B527 - standard test method for tap density of metal powders and compounds. ASTM B Stand, p 15-18. 10.1520/ B0527-15.2

25. Spierings AB, Schneider M, Eggenberger M (2011) Comparison of density measurement techniques for additive manufactured metallic parts. Rapid Prototyp J 17(5):380-386. ISSN 13552546. $10.1108 / 13552541111156504$

26. Lukas H, Livia H, Adriaan S, Konrad W, Kirstin R, Stefan Z, Gerhard JL (2021) The influence of particle shape, powder flowability, and powder layer density on part density in laser powder bed fusion. Metals (Basel) 11(3):1-15. ISSN 20754701. 10.3390/ met11030418

27. Matthew K, Hui Z, Jesse Z (2009) Characterization of powder flow: static and dynamic testing. Powder Technol 194(3):239-245. ISSN 00325910. 10.1016/j.powtec.2009.05.001

28. Abele HS, Fischer J, Siedelhofer C (2011) Selective laser melting of porous structures. Proc 22th Int Solid Free Fabr Symp, 19(4):680-695, 2011. 10.3724/SP.J.1042.2011.00580

29. Galina K, Jan H, Joachim G, Guillermo R (2016) Correlation between porosity and processing parameters in tial6v4 produced by selective laser melting. Mater Design 105:160 - 170. ISSN 0264-1275. https://doi.org/10.1016/j.matdes.2016.05.070. http:// www.sciencedirect.com/science/article/pii/S0264127516306761

30. Dilip JSJ, Shanshan Z, Chong T, Kai Z, Chris R, Deepankar P, Brent $S$ (2017) Influence of processing parameters on the evolution of melt pool, porosity, and microstructures in Ti-6Al-4V alloy parts fabricated by selective laser melting. Prog Addi. Manuf 2(3):157-167. ISSN 23639520. 10.1007/s40964-017-0030-2

31. Qilin G, Cang Z, Minglei Q, Lianghua X, Mohammad S, Hojjatzadeh H, Luis IE, Niranjan DP, Kamel F, Tao S, Lianyi C (2020) Insitu full-field mapping of melt flow dynamics in laser metal additive manufacturing. Addit Manuf, 31:100939. ISSN 22148604. 10.1016/j.addma.2019.100939

32. Mukherjee T, Zuback JS, De A, DebRoy T (2016) Printability of alloys for additive manufacturing. Sci Rep 6:1-8. ISSN 20452322. 10.1038/srep19717

33. Yousub L, Zhang W (2015) Mesoscopic simulation of heat transfer and fluid flow in laser powder bed additive manufacturing. In Solid Free Fabr Proc, p 1154-1165. University of Texas at Austin

34. Gusarov AV, Smurov I (2010) Modeling the interaction of laser radiation with powder bed at selective laser melting. Phys Procedia, 5:381-394. ISSN 18753892. 10.1016/j.phpro.2010.08.065

Publisher's Note Springer Nature remains neutral with regard to jurisdictional claims in published maps and institutional affiliations. 